\section{A) Check for updates}

Cite this: Polym. Chem., 2017, 8 , 4576

Received 30th March 2017, Accepted 2nd July 2017

DOI: $10.1039 / \mathrm{c} 7 \mathrm{py} 00535 \mathrm{k}$ rsc.li/polymers

\title{
Poly(acryloyl hydrazide), a versatile scaffold for the preparation of functional polymers: synthesis and post-polymerisation modification $\dagger$
}

\author{
Daniel N. Crisan, ${ }^{a}$ Oliver Creese, ${ }^{a}$ Ranadeb Ball, ${ }^{a}$ Jose Luis Brioso, ${ }^{a}$ Ben Martyn, (iD b \\ Javier Montenegro (D) *c and Francisco Fernandez-Trillo (iD *a
}

\begin{abstract}
Here we present the synthesis and post-polymerisation modification of poly(acryloyl hydrazide), a versatile scaffold for the preparation of functional polymers: poly(acryloyl hydrazide) was prepared from commercially available starting materials in a three step synthesis on a large scale, in good yields and high purity. Our synthetic approach included the synthesis of a Boc-protected acryloyl hydrazide, the preparation of polymers via RAFT polymerisation and the deprotection of the corresponding Boc-protected poly(acryloyl hydrazide). Post-polymerisation modification of poly(acryloyl hydrazide) was then demonstrated using a range of conditions for both hydrophilic and hydrophobic aldehydes. These experiments demonstrate the potential of poly(acryloyl hydrazide) as a scaffold in the synthesis of functional polymers, in particular those applications where in situ screening of the activity of the functionalised polymers may be required (e.g. biological applications).
\end{abstract}

\section{Introduction}

There is an increasing interest in developing polymers for biomedical applications and we now increasingly see polymers that play an "active" role in biology and reproduce or interact with biological functions. Representative examples include glycopolymers that mimic and interfere with glycan recognition, ${ }^{1-4}$ polymers for gene delivery that mimic some of the characteristics of viral vectors, ${ }^{5-9}$ or therapeutic polymers such as antimicrobial polymers. ${ }^{10-13}$ One common requirement when developing polymers for these applications is the need to synthesise libraries of polymers that incorporate highly functional monomers based on for instance carbohydrates, amine or cationic moieties. However, and despite the availability of a large toolbox for the synthesis of polymers, ${ }^{14-17}$ there are still many functional groups which are incompatible with existing polymerisation techniques. A common approach to solve this incompatibility is to employ post-polymerisation

\footnotetext{
${ }^{a}$ School of Chemistry, University of Birmingham B15 2TT, UK.

E-mail:f.fernandez-trillo@bham.ac.uk

${ }^{b}$ School of Chemistry, University of Warwick CV47AL, UK

${ }^{c}$ Departamento de Química Orgánica y Centro Singular de Investigación en Quimica Biolóxica e Materiais Moleculares (CIQUS), Universidade de Santiago de Compostela E-15782, Spain. E-mail: javier.montenegro@usc.es

$\dagger$ Electronic supplementary information (ESI) available: Additional NMR and UV-Vis spectra, additional tables and proposed mechanism for impurities. See DOI: $10.1039 / \mathrm{c} 7 \mathrm{py} 00535 \mathrm{k}$
}

modification, ${ }^{18-20}$ where polymer "scaffolds" are made with reactive moieties that are inert to the polymerisation conditions, but can then be modified post-polymerisation to give other functional groups. The success of this strategy relies on the nearly quantitative conversion of this initial reactive moiety to give functionalised polymers. Not surprisingly, these post-polymerisation protocols have often relied on highly efficient and orthogonal chemistries, i.e. click chemistries. ${ }^{21-26}$

Despite the progress in this area, one potential limitation of these post-polymerisation strategies is the low aqueous solubility and stability of some of these reactive polymer scaffolds. Thus, additional steps must be employed following postpolymerisation modification and prior to biological evaluation, including the removal of protecting groups. Moreover, the current paradigm assumes that candidate polymers need to be isolated/purified prior to biological evaluation. However, this is inefficient, time-consuming and expensive, since efforts are invested in isolating candidate polymers that do not show any biological activity. The introduction of automation to polymer synthesis has the potential to facilitate some of these steps, ${ }^{27}$ but it can result in even larger libraries of functional polymers, with the subsequent increase in cost associated to purification and isolation.

To address some of these limitations, we have recently reported the application of poly(acryloyl hydrazide) as a reactive polymer scaffold for the in situ preparation of polymeric gene vectors for the delivery of siRNA. ${ }^{27}$ Polymers carrying hydrazides as reactive moieties are ideal to develop a post-poly- 
merisation strategy that works in aqueous conditions, and that eliminates purification and isolation steps following post-polymerisation modification. The coupling reaction between hydrazides and aldehydes is orthogonal to many biologically relevant functional groups (e.g. hydroxyls, acids or amines) and produces water as a by-product. ${ }^{28}$ Thus, in the absence of interference from the used aldehydes, there is no need to purify candidate polymers after the post-polymerisation reaction. This is often the case for biological applications that benefit from a multivalent effect such as lectin binding. ${ }^{29}$ Also, the formed hydrazone is relatively stable at physiological $\mathrm{pH}$ (i.e. $5-7),{ }^{29}$ and the biological activity of the functional polymers can be evaluated without having to reduce the hydrazone. ${ }^{27,30}$ Finally, hydrazides are weakly protonated under physiological conditions $\left(\mathrm{p} K_{\mathrm{a}} \mathrm{H} \sim 5\right)$ and thus poly(hydrazide)s are normally non-toxic. ${ }^{27}$ Despite all of these features, the use of poly(hydrazide)s as a reactive scaffold had been limited to the preparation of glycopolymers, ${ }^{29,31}$ and for $\mathrm{pH}$-responsive drug delivery. ${ }^{32-36}$ Alternative elegant strategies using poly (alkoxyamine) $\mathrm{s}^{37,38}$ and poly(aldehyde) $\mathrm{s}^{39-41}$ have also been explored.

Here, we evaluate the potential of poly(acryloyl hydrazide) as a reactive scaffold for post-polymerisation functionalisation. First, we report the synthesis of poly(acryloyl hydrazide) from a Boc-protected monomer using RAFT polymerisation. Then, we evaluate its functionalisation by reacting with aldehydes and explore a range of conditions. Overall, our results demonstrate that poly(acryloyl hydrazide) is a versatile reactive scaffold that can mediate the synthesis of polymers carrying a wide range of functionalities, including acidic and basic moieties, biologically relevant functionalities, and aliphatic and aromatic side-chains. The efficiency of the hydrazide-aldehyde coupling can be modulated by tuning the reaction conditions, including the use of both aqueous and organic conditions, to yield polymers with a consistent degree of functionalisation.

\section{Experimental}

\section{Materials}

2-((Ethylthio)carbonothioyl)thio-2-methylpropanoic acid (CTA1) was synthesised according to protocols described in the literature. ${ }^{42}$ Cyanomethyl methyl(4-pyridyl)carbamodithioate (CTA2) was purchased from Sigma-Aldrich ${ }^{\circledR}$ and used without further purification. 2,2'-Azobis[2-(2-imidazolin-2-yl)propane] dihydrochloride (VA-044) was purchased from Fluorochem and used without further purification. All other chemicals were purchased from Sigma-Aldrich $\AA$, Fisher Scientific ${ }^{\circledR}$, VWR $®$ or Acros ${ }^{\circledR}$, and used without further purification. All solvents were Reagent grade or above, purchased from Sigma-Aldrich ${ }^{\circledR}$, Fisher Scientific ${ }^{\circledR}$ or VWR ${ }^{\circledR}$, and used without further purification.

Nuclear Magnetic Resonance (NMR) spectra were recorded on either a Bruker Avance III $300 \mathrm{MHz}$ or a Bruker Avance III $400 \mathrm{MHz}$ spectrometer. Chemical shifts are reported in ppm (units) referenced to the following solvent signals: dimethylsulfoxide (DMSO)- $d_{6} \mathrm{H} 2.50$ and $\mathrm{D}_{2} \mathrm{O} \quad \mathrm{H}$ 4.79. Infrared (IR) spectra were recorded on a PerkinElmer Spectrum Two FT-IR spectrometer. Ultraviolet-visible (UV-vis) spectra were recorded on a Cary 50 Spectrophotometer. Gel Permeation Chromatography (GPC) was performed with a Shimadzu Prominence LC-20A fitted with a Thermo Fisher Refractomax 521 Detector and a SPD20A UV-vis Detector. Boc-Protected poly (acryloyl hydrazide) (Boc- $\mathbf{P}_{\boldsymbol{x}}$ ) was analysed using $0.05 \mathrm{M} \mathrm{LiBr}$ in dimethylformamide (DMF) at $60{ }^{\circ} \mathrm{C}$, or $0.005 \mathrm{M} \mathrm{NH}_{4} \mathrm{BF}_{4}$ in $\mathrm{DMF}$ at $50{ }^{\circ} \mathrm{C}$, as the eluent and a flow rate of $1 \mathrm{~mL} \mathrm{~min}{ }^{-1}$. The instrument was fitted with a Polymer Labs PolarGel guard column $(50 \times 7.5 \mathrm{~mm}, 5 \mu \mathrm{m})$ followed by two PLGel PL1110-6540 columns $(300 \times 7.5 \mathrm{~mm}, 5 \mu \mathrm{m})$. Molecular weights were calculated based on a standard calibration method using polymethylmethacrylate. Poly(acryloyl hydrazide) $\mathbf{P}_{\boldsymbol{x}}$ was analysed using Dulbecco's Phosphate Buffered Saline 0.0095 M $\left(\mathrm{PO}_{4}\right)$ without $\mathrm{Ca}$ and $\mathrm{Mg}$ as the eluent and a flow rate of $1 \mathrm{~mL} \mathrm{~min}^{-1}$. The instrument was fitted with an Agilent PL aquagel-OH column $(300 \times 7.5 \mathrm{~mm}, 8 \mathrm{~mm})$ and run at $35^{\circ} \mathrm{C}$.

Dialysis was carried out in deionised water at room temperature for a minimum of 48 hours using a Spectra/Por 61000 Molecular weight cut-off (MWCO) $38 \mathrm{~mm}$ width membrane.

\section{tert-Butyl-2-acryloylhydrazine-1-carboxylate (M1)}

Acrylic acid (3.8 ml, $55.00 \mathrm{mmol})$ and tert-butyl carbazate $(8.9 \mathrm{~g}, 66.0 \mathrm{mmol})$ were dissolved in $\mathrm{a}_{2} \mathrm{O}$ : THF mixture $(2: 1$, $180 \mathrm{ml}$ ) at r.t. $N$-(3-Dimethylaminopropyl)- $N$ '-ethylcarbodiimide hydrochloride $(11.8 \mathrm{~g}, 61.3 \mathrm{mmol})$ was added in portions to the solution over 15 minutes and left stirring for $3 \mathrm{~h}$. The solution was extracted with ethyl acetate (EtOAc) $(3 \times 75 \mathrm{ml})$ and the organic layer was washed with $0.1 \mathrm{M} \mathrm{HCl}(3 \times 75 \mathrm{ml})$, $\mathrm{H}_{2} \mathrm{O}(50 \mathrm{ml})$ and brine $(2 \times 50 \mathrm{ml})$. The organic phase was dried with $\mathrm{Na}_{2} \mathrm{SO}_{4}$ and the solvent was removed under reduced pressure to afford the crude product as a white solid. The crude product was purified by recrystallization from EtOAc (70 ${ }^{\circ} \mathrm{C}$ to r.t.) to afford a white crystalline powder $(5.1 \mathrm{~g}, 50 \%$ yield): $R_{\mathrm{f}}=0.87$ (100\% EtOAc); ${ }^{1} \mathrm{H}-\mathrm{NMR}\left(300 \mathrm{MHz}, \mathrm{DMSO}-d_{6}\right)$ $\delta(\mathrm{ppm}) 9.79(\mathrm{~s}, 1 \mathrm{H}), 8.84(\mathrm{~s}, 1 \mathrm{H}), 6.17-6.20$ (m, 2H), 5.69 (dd, $\left.{ }^{3} J_{H, H}=7.8,4.5 \mathrm{~Hz}, 1 \mathrm{H}\right), 1.40(\mathrm{~s}, 9 \mathrm{H}) .{ }^{13} \mathrm{C}-\mathrm{NMR}(100 \mathrm{MHz}, \mathrm{DMSO}-$ $\left.d_{6}\right) \delta(\mathrm{ppm}) 164.3(\mathrm{~s}), 155.3(\mathrm{~s}), 129.4(\mathrm{~d}), 126.2(\mathrm{t}), 79.2(\mathrm{~s})$, 28.1 (q). IR (neat) $\nu_{\max } 3311$ (m sh, N-H), 3221 (m sh, N-H), 2981 (w sh, C-H), 1715 (s sh, C=O), 1668 (s sh, C=O) $\mathrm{cm}^{-1}$.

\section{Acryloylhydrazide hydrochloride (M2)}

Hydrazide $\mathbf{M 1}(2.0 \mathrm{~g}, 10.7 \mathrm{mmol})$ in $1 \mathrm{M} \mathrm{HCl}_{(\mathrm{aq})}(80 \mathrm{ml})$ was stirred at $0{ }^{\circ} \mathrm{C}$ for $24 \mathrm{~h}$ and stirred a further $48 \mathrm{~h}$ at r.t. Excess $\mathrm{HCl}$ was removed under reduced pressure without heating the solution. Water was removed by lyophilisation to afford a white crystalline powder $\left(0.9 \mathrm{~g}, 68 \%\right.$ yield): ${ }^{1} \mathrm{H}-\mathrm{NMR}(300 \mathrm{MHz}$, DMSO- $\left.d_{6}\right) \delta(\mathrm{ppm}) 11.44(\mathrm{~s}, 1 \mathrm{H}), 6.26-6.39(\mathrm{~m}, 2 \mathrm{H}), 5.85$ (dd, $\left.{ }^{3} J_{H, H}=9.6,2.5 \mathrm{~Hz}, 1 \mathrm{H}\right) .{ }^{13} \mathrm{C}-\mathrm{NMR}\left(100 \mathrm{MHz}, \mathrm{DMSO}-d_{6}\right) \delta(\mathrm{ppm})$ 163.9 (s), 129.1 (d), 127.7 (t).

\section{Poly(tert-butyl-2-acryloylhydrazine-1-carboxylate) (Boc-P $\left.{ }_{x}\right)$}

In a typical experiment, a solution of 4,4'-azobis(4-cyanovaleric acid) (V-501) $(18.4 \mathrm{mg}, 64.0 \mu \mathrm{mol})$ in DMSO $(1.5 \mathrm{~mL})$ and a solution of CTA1 $(72.3 \mathrm{mg}, 32.2 \mu \mathrm{mol})$ in DMSO $(1.5 \mathrm{~mL})$ were 
added sequentially to a solution of tert-butyl-2-acryloylhydrazine-1-carboxylate $(3.0 \mathrm{~g}, 16.1 \mathrm{mmol})$ in DMSO $(14.9 \mathrm{~mL})$. A $50 \mu \mathrm{L}$ aliquot of this solution was taken at this stage to aid in the calculation of conversion. The reaction mixture was then sealed and degassed with Argon for $30 \mathrm{~min}$. The degassed solution was left to react at $70{ }^{\circ} \mathrm{C}$ for $7 \mathrm{~h}$. The reaction was stopped by allowing it to cool down to room temperature and by exposing it to air. A $50 \mu \mathrm{L}$ aliquot of this solution was taken at this stage to aid in the calculation of conversion. The polymer was purified by dialysis against water. The water was removed by lyophilisation and by drying in a desiccator with $\mathrm{P}_{2} \mathrm{O}_{5}$ to afford $2.2 \mathrm{~g}$ of Boc- $\mathbf{P}_{40}$ as an off-white powder $(73 \%$ yield). UV (DMSO) $\lambda_{\max } 300 \mathrm{~nm} .{ }^{1} \mathrm{H}-\mathrm{NMR}\left(300 \mathrm{MHz}, \mathrm{DMSO}-d_{6}\right)$ $\delta(\mathrm{ppm}) 9.22(\mathrm{br}, 1 \mathrm{H}, \mathrm{NH}), 8.60(\mathrm{br}, 1 \mathrm{H}, \mathrm{NH}), 2.03(\mathrm{br}, 1 \mathrm{H}$, $\left.\mathrm{CH}_{2} \mathrm{CH}\right), 1.41$ (br, $11 \mathrm{H}, 9 \mathrm{H}$ in $\mathrm{C}\left(\mathrm{CH}_{3}\right)_{3}, 2 \mathrm{H}$ in $\left.\mathrm{CHCH}_{2}\right)$. Conversion 86\%. DP (UV-vis) 45.

\section{Poly(acryloyl hydrazide) $\mathbf{P}_{\boldsymbol{x}}$}

In a typical experiment, trifluoroacetic acid (TFA) (15 mL) was added dropwise to poly(tert-butyl-2-acryloylhydrazine-1-carboxylate) (Boc-P $\left.\mathbf{P}_{40}\right)(1.5 \mathrm{~g})$ and the yellow solution was stirred at r.t. overnight. Excess of TFA was removed by blowing a steady stream of Argon and the resulting oil was diluted in water (15 mL). The $\mathbf{P}_{\mathbf{4 0}}$. TFA salt formed was neutralised by adding $\mathrm{NaHCO}_{3}$ until no foaming was observed. The colourless solution was allowed to stir overnight. The crude polymer was purified by dialysis against water. The water was removed by lyophilisation and by drying in a desiccator with $\mathrm{P}_{2} \mathrm{O}_{5}$ to afford $650 \mathrm{mg}$ of $\mathbf{P}_{40}$ as a white powder (92\%). ${ }^{1} \mathrm{H}-\mathrm{NMR}(300 \mathrm{MHz}$, $\left.\mathrm{D}_{2} \mathrm{O}\right) \delta(\mathrm{ppm})$ 1.59-2.08 (br m, (3.DP)H), 1.01 (s, 3H), 0.95 (s, $3 \mathrm{H}) .{ }^{13} \mathrm{C}-\mathrm{NMR}\left(100 \mathrm{MHz}, \mathrm{D}_{2} \mathrm{O}\right) \delta$ (ppm) 174.9 (s), 40.2-40.5 (d), 34.4-35.7 (d). DP ( $\left.{ }^{1} \mathrm{H}-\mathrm{NMR}\right)$ 40. IR (neat) $\nu_{\max } 3254$ (w br, N$\mathrm{H}), 1609$ (m br, $\mathrm{C}=\mathrm{O}), 1428$ ( $\mathrm{s} \mathrm{sh}) \mathrm{cm}^{-1}$.

\section{Conjugation of poly(acryloyl hydrazide) $\mathbf{P}_{\boldsymbol{x}}$ with aldehydes}

In a typical experiment, $200 \mu \mathrm{l}$ of a $100 \mathrm{mM}+$ solution of $\mathbf{P}_{\boldsymbol{x}}$ in acetic acid $(\mathrm{AcOH}) / \mathrm{D}_{2} \mathrm{O}$ buffer $\S$ was mixed with $200 \mu \mathrm{l}$ of a $100 \mathrm{mM}$ solution of the aldehyde in the required solvent. This mixture was shaken at $60{ }^{\circ} \mathrm{C}$ for $24 \mathrm{~h}$. 1 Polymers were used without further purification.

\section{Results and discussion}

\section{Poly(acryloyl hydrazide) synthesis}

Although several conditions have been reported in the literature for the synthesis of poly(acryloyl hydrazide) and poly(methacryloyl hydrazide), ${ }^{29,32-34}$ including the recently

$\$ 100 \mathrm{mM}$ in hydrazide moieties. Final concentration of hydrazides in solution = $50 \mathrm{mM}$.

$\S \mathrm{AcOH} / \mathrm{D}_{2} \mathrm{O}$ buffer $=100 \mathrm{mM} \mathrm{AcOH}$ in $\mathrm{D}_{2} \mathrm{O}$ at $\mathrm{pH}$ 2.9. Other buffers used include $5 \% \mathrm{AcOH}$ in $\mathrm{D}_{2} \mathrm{O}$ pH 2.9 (Table 3), $100 \mathrm{mM} \mathrm{Na}_{2} \mathrm{HPO}_{4}$ in $\mathrm{D}_{2} \mathrm{O}$ pH 9.1 (Table 3 ) and $95 \%$ DMSO- $d_{6} 5 \% \mathrm{AcOH}$ in $\mathrm{D}_{2} \mathrm{O}$ (Table 4 , Tables $\mathrm{S} 2-\mathrm{S} 4 \dagger$ ) final $\mathrm{pH}=2.9$.

ๆ In aqueous conditions, samples can be incubated for only $2 \mathrm{~h}$ at r.t. reported polymerisation of unprotected poly(methacryloyl hydrazide) at $\mathrm{pH} 0,{ }^{43}$ we decided to explore a synthetic route that could avoid the use of an excess of toxic hydrazine. Two synthetic strategies to achieve the target poly(acryloyl hydrazide) $\mathbf{P}_{\boldsymbol{x}}$ starting from commercially available tert-butyl 2-acryloylhydrazine-1-carboxylate were thus investigated (Scheme 1). In both cases, reversible addition-fragmentation chain transfer (RAFT) polymerisation was employed because of its versatility for the preparation of acrylamide based polymers. ${ }^{44-46}$ Our initial attempts focused on the polymerisation of the deprotected acryloyl hydrazide (M2, Scheme 1, bottom). However, this strategy proved challenging. Initial polymerisation of this monomer was done with CTA1, a chain transfer agent previously used in our group, ${ }^{47}$ using acetate buffer ( $\mathrm{pH} 5$ ) at $70{ }^{\circ} \mathrm{C}$. This $\mathrm{pH}$ was selected as a compromise to maximise solubility of the RAFT agent and protonation of the hydrazide. Although monomer consumption was observed rapidly by ${ }^{1} \mathrm{H}$ NMR, no characteristic broad polymer peaks were seen in the expected alkyl region 1.9-1.1 ppm (Fig. S3, ESI $\dagger$ ). Instead, the appearance of broad peaks at 2.86 and 2.21 ppm suggested the formation of oligomeric compounds, probably resulting from the Michael addition of the nitrogen in one hydrazide to the $\alpha, \beta$-unsaturated system in another monomer. Moreover, the characteristic yellow colour of the solution due to CTA1 also disappeared over time, suggesting that degradation of the transfer agent was occurring. We think both results indicate that possibly at this $\mathrm{pH}$ the hydrazide monomer was not fully protonated and thus remained strongly nucleophilic. Thus, we attempted the polymerisation using CTA2, a RAFT agent whose reactivity can be tuned as a function of the $\mathrm{pH}$ of the polymerisation solution. ${ }^{48}$ This RAFT agent is suitable for the polymerisation of challenging monomers and it could be used in aqueous conditions at low $\mathrm{pH}$ to ensure full protonation of the hydrazide monomer. Two conditions were thus explored ([monomer]: [CTA2]: [ $p$-toluene sulfonic acid] at $100: 1: 1$ and $100: 1: 200$ ratios), but in both cases no polymer formation was observed.

In light of these issues with the polymerisation of acryloyl hydrazide, the polymerisation of the protected monomer (M1) in DMSO at $70{ }^{\circ} \mathrm{C}$ was attempted instead. In this case, a decrease in alkene signals in ${ }^{1} \mathrm{H}$-NMR could be observed, as well as broadening of $\mathrm{N}-\mathrm{H}$ signals and the tert-butyl signals, and the appearance of new broad signals in the alkyl region (Fig. S4, ESI $\dagger$ ). To determine optimum reaction times, we carried out kinetic studies of the reaction by taking aliquots at different intervals and monitoring the conversion (c) by ${ }^{1} \mathrm{H}-\mathrm{NMR}$. As expected for any free radical polymerisation, the reaction followed first order kinetics, at least during the initial stages of the polymerisation (Fig. 1). However, a deviation from linearity could be observed when the natural logarithm of the relative monomer concentration was plotted against time (Fig. 1A), suggesting termination may be occurring at later stages of the reaction. A similar behaviour has been observed in the polymerisation of other (meth)acrylamides, ${ }^{49}$ which has been assigned to the degradation of the polymer's trithiocarbamate end-group via an amide backbiting mechan- 

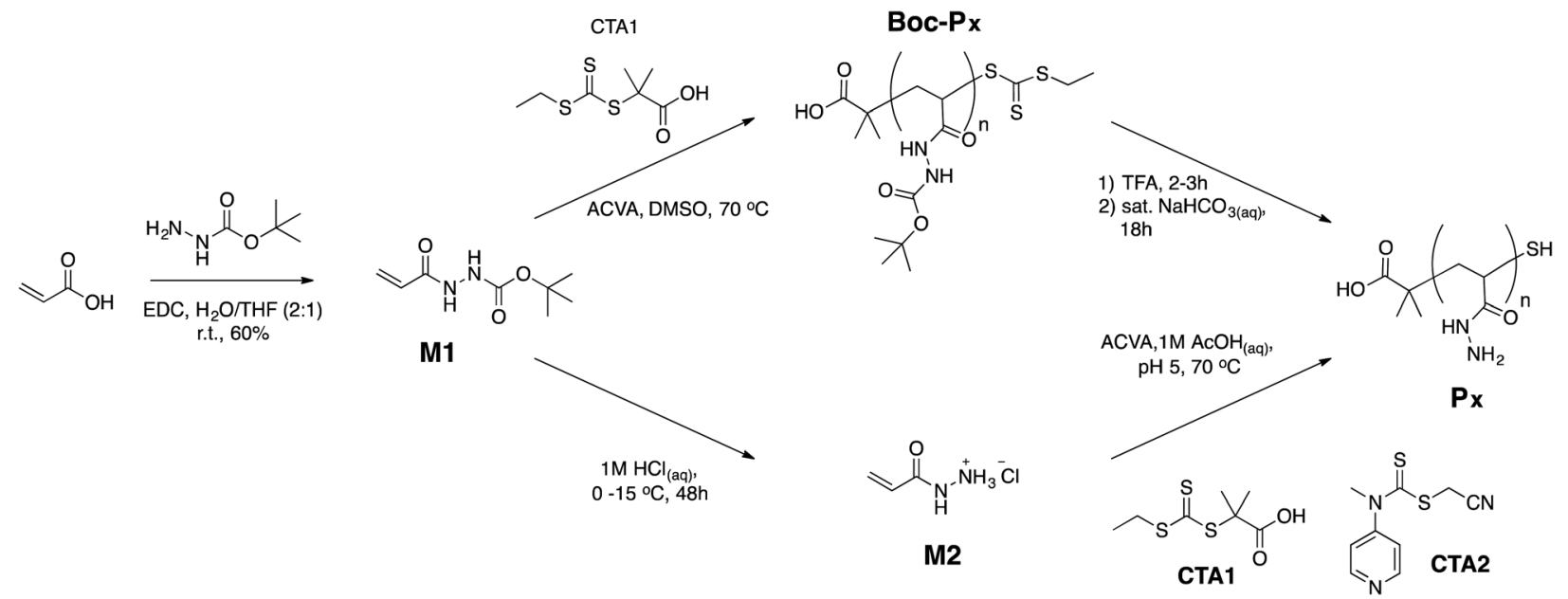

Scheme 1 Synthetic strategies investigated for the synthesis of poly(acryloyl hydrazide).
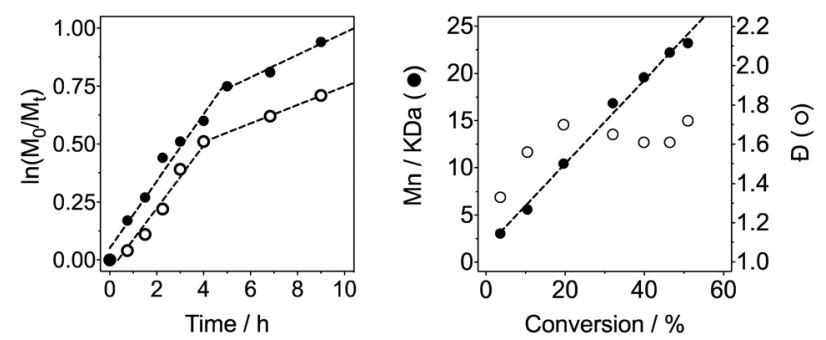

Fig. 1 Left: Representative linear plot of $\ln [\mathrm{M}]_{0} /[\mathrm{M}]_{t}$ vs. time. Conditions: $[\mathrm{M}]=0.9 \mathrm{M},[\mathrm{M}] /[\mathrm{CTA}] /[\mathrm{V}-501]=100 / 1 / 0.2 ; \mathrm{O}:[\mathrm{M}]=0.9$ M, $[M] /[C T A] /[V-501]=100 / 1 / 0.11$. Right: Representative plot of measured number average molecular weight $\left(M_{n}\right)$ vs. conversion $(\bullet)$ and $\Theta$ vs. conversion (O). $M_{t}, M_{n}$ and $\oslash$ calculated by GPC using $0.005 \mathrm{M}$ $\mathrm{NH}_{4} \mathrm{BF}_{4}$ in DMF at $50^{\circ} \mathrm{C}$ as the eluent.

ism. ${ }^{50}$ In our case, a deviation from linearity was observed, even when polymerisations were performed at $50{ }^{\circ} \mathrm{C}$ and $44{ }^{\circ} \mathrm{C}$, using suitable initiators for those temperatures (Fig. S7 $\dagger$ ). When the reaction was carried out at $30^{\circ} \mathrm{C}$, only $40 \%$ conversion was achieved after $24 \mathrm{~h}$. Similarly, reduction of the amount of initiator used had no major effect on the kinetics of the reaction, beyond the appearance of a small induction period (Fig. 1A, O). As in most previous cases, the reaction slowed down at higher conversions, suggesting termination. This effect agreed with the observed increase in the dispersity $(D)$ in molecular weight as the polymerisation progressed (Fig. 1B).

Nonetheless, the tested conditions allowed us to predict the molecular weight of the formed polymers (Fig. 1B), and thus we synthesised different polymer batches with degrees of polymerisation (DPs) ranging from 43 to 127 and dispersities between 1.38-1.51 (Table 1). Attempts to prepare polymers of larger DPs (i.e. $\sim 200$ monomer units) lead to polymers with higher $\oplus$ values, despite having reached similar monomer conversions than the other polymerisations performed (Table 1). UV-Vis analysis of all polymers revealed the presence of a
Table 1 Boc-protected poly(acryloyl hydrazide)s (Boc- $P_{x}$ ) described in this paper

\begin{tabular}{lclcrl}
\hline Polymer & {$[\mathrm{M}] /[\mathrm{CTA}]$} & $c^{a}$ & $\mathrm{DP}_{\mathrm{th}}{ }^{b}$ & \multicolumn{1}{c}{$M_{\mathrm{n}}{ }^{c}$} & $D^{c}$ \\
\hline Boc-P $_{\mathbf{4 0}}$ & 50 & $86 \%$ & 43 & 9810 & 1.38 \\
Boc-P $_{\mathbf{8 0}}$ & 99 & $79 \%$ & 78 & 20306 & 1.52 \\
Boc-P $_{\mathbf{1 3 0}}$ & 151 & $84 \%$ & 127 & 31552 & 1.51 \\
Boc-P $_{\mathbf{1 7 0}}$ & 195 & $87 \%$ & 170 & 44826 & 1.95
\end{tabular}

${ }^{a}$ Conversion (c) calculated from ${ }^{1} \mathrm{H}$ NMR peak integration of alkene signals versus a known standard. ${ }^{b}[\mathrm{M}] /[\mathrm{CTA}] \times c .{ }^{c}$ Calculated by GPC using 0.05 $\mathrm{M} \mathrm{LiBr}$ in DMF at $60^{\circ} \mathrm{C}$ as the eluent.

characteristic band at around $300 \mathrm{~nm}$ (Fig. S5, ESI†े), in close proximity to that of the transfer agent used (Fig. 2). The presence of this band suggested that all polymers still retained some of the RAFT agent used. There were small differences in the wavelength for maximum absorption $\left(\lambda_{\max }\right)$ implying that the chemical environment around this chain transfer agent was changing as the degree of polymerisation was increased.

The polymers were then deprotected by reacting in neat TFA for 2-3 $\mathrm{h}$ followed by dilution in water and saturation with
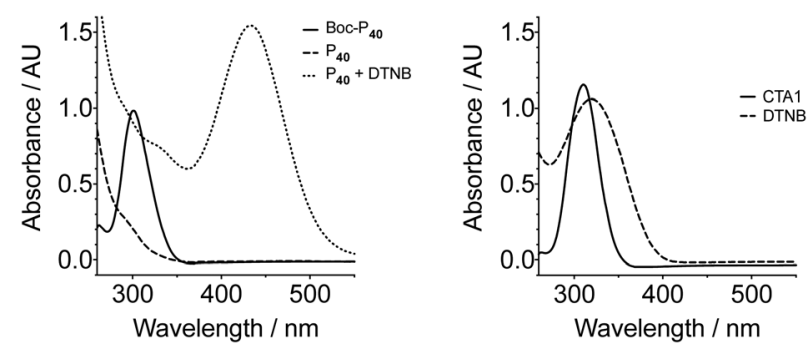

Fig. 2 Representative UV-Vis spectra of the polymers prepared in this work and the reaction of the poly(acryloyl hydrazide) and DTNB. UV-Vis spectra for CTA1 and DTNB are shown for comparison. Conditions: Boc$\mathrm{P}_{40}$ and CTA1 were carried out in DMSO. $\mathrm{P}_{40}, \mathrm{P}_{40}+$ DNTB and DTNB were carried out in water at r.t. $\left[\right.$ Boc $\left.-P_{40}\right]=0.63 \mathrm{mg} \mathrm{ml}^{-1},[C T A]=$ $0.03125 \mathrm{mg} \mathrm{ml}^{-1},\left[\mathrm{P}_{40}\right]=1.33 \mathrm{mg} \mathrm{ml}^{-1},\left[\right.$ DTNB] $=0.02 \mathrm{mg} \mathrm{ml}^{-1}$. 
$\mathrm{NaHCO}_{3}$. This way the excess of TFA was neutralised and the hydrazides deprotonated to afford the target poly(acryloyl hydrazide) $\mathbf{P}_{\boldsymbol{x}}$. We also observed the loss of the thiocarbonylthio group to afford a thiol, possibly because of the strongly basic conditions employed during neutralisation $(\mathrm{pH}$ $\mathrm{NaHCO}_{3}$ (sat) 12). For example, the UV-Vis signal at $300 \mathrm{~nm}$ observed for Boc- $\mathbf{P}_{40}$ (Fig. 2, solid line), could not be observed for the deprotected polymer $\mathbf{P}_{\mathbf{4 0}}$ (Fig. 2, dashed line). Moreover, when this deprotected polymer was reacted with 5,5'-dithiobis(2-nitrobenzoic acid) (DNTB), a colorimetric dye used for the identification of thiols, ${ }^{51}$ a characteristic peak at $435 \mathrm{~nm}$ could be observed (Fig. 2, dotted line), representative of the formed 5-mercapto-2-nitrobenzoic acid. No effect over the molecular weight distribution of this polymer could be observed following basic treatment, suggesting that coupling of the polymer chains through disulfide oxidation was minimal under these conditions (Fig. S8 $\dagger$ ).

NMR analysis of the target poly(acryloyl hydrazide)s $\mathbf{P}_{\boldsymbol{x}}$ confirmed the absence of the Boc signal (Fig. S6, ESI $\dagger$ ). Moreover, signals corresponding to the methyls originating from the RAFT agent could now be clearly identified at 0.94 and $1.00 \mathrm{ppm}$, and were used to determine the degree of polymerisation (Table 2). Again, these values were in close agreement to those expected from the conversion during the polymer synthesis, validating the use of the described conditions for the synthesis of these polymers.

Table 2 Poly(acryloyl hydrazide)s $\left(\mathbf{P}_{x}\right)$ described in this paper

\begin{tabular}{lcll}
\hline Polymer & $\mathrm{DP}_{\mathrm{NMR}}{ }^{a}$ & $M_{\mathrm{n}}{ }^{b}$ & $D^{b}$ \\
\hline $\mathbf{P}_{\mathbf{4 0}}$ & 49 & 10918 & 1.37 \\
$\mathbf{P}_{\mathbf{8 0}}$ & 106 & 18446 & 1.33 \\
$\mathbf{P}_{\mathbf{1 3 0}}$ & 136 & $-^{c}$ & $-^{c}$ \\
$\mathbf{P}_{\mathbf{1 7 0}}$ & 162 & $\mathbf{C}^{c}$ & ${ }^{c}$
\end{tabular}

${ }^{a}$ Calculated from ${ }^{1} \mathrm{H}$ NMR peak integration of methyl signals at 0.94 and $1.00 \mathrm{ppm}$ versus alkyl backbone. ${ }^{b}$ Calculated by GPC. ${ }^{c}$ Samples were not soluble in GPC eluent.

\section{Aldehydes coupling to polymer}

As described in our previous work with siRNA, 4-imidazolecarboxaldehyde (1) was used as a model hydrophilic aldehyde to identify conditions for the functionalisation of the polymer scaffold. ${ }^{27}$ As reported, the coupling of 1 with poly(acryloyl hydrazide) $\mathbf{P}_{\boldsymbol{x}}$ could be performed in $100 \mathrm{mM} \mathrm{AcOH} / \mathrm{D}_{2} \mathrm{O}$ buffer with varying amounts of aldehyde in relative short times (1-4 h). When we looked at these conditions in more detail, we identified that the duration of the coupling was not dependent on the number of equivalents added, with 0.3 and 0.6 eq. of 1 requiring $1 \mathrm{~h}$ for a complete coupling to be observed (Fig. 3, Table S1 $\dagger$ ). ${ }^{27}$ For 0.9 eq., no full consumption of aldehyde was observed even after $24 \mathrm{~h}$ (Fig. S9, ESI $\dagger$ ). However, for these equivalents, the amount of free aldehyde $(\sim 27 \%)$ was more or less constant at different intervals, suggesting that $\sim 65-66 \%$ of the hydrazide side-chains had reacted. This degree of functionalisation is what we had reported before and in agreement with other examples in the literature. ${ }^{27,29}$

As just discussed, the degree of functionalisation remained constant under the conditions $\left(100 \mathrm{mM}\right.$ AcOH in $\mathrm{D}_{2} \mathrm{O}$ at $\mathrm{pH}$ 2.9) used for the functionalisation, and no regeneration of the aldehyde was observed. To further probe this, $\mathbf{P}_{\mathbf{4 0}}$ was incubated with 0.6 eq. of 4-imidazolecarboxaldehyde (1), enough aldehyde to ensure full reactivity with the polymer backbone. The degree of functionalisation was evaluated by NMR over a period of $48 \mathrm{~h}$, and no signal for the free aldehyde was observed at any point of the experiment (Fig. 3, right). A similar effect was observed when the degree of functionalisation was monitored for the reaction with 1 eq. of the aldehyde, with no significant changes in the amount of free aldehyde observed with time (Fig. S10 $\dagger$ ). These experiments suggested that the system had reached thermodynamic equilibrium, and any aldehyde dissociation would be compensated by the reformation of hydrazone. Remarkably, when the samples were diluted twofold following initial incubation for $2 \mathrm{~h}$, no regeneration of the aldehydes could be observed, suggesting that the thermodynamic equilibrium was not significantly affected
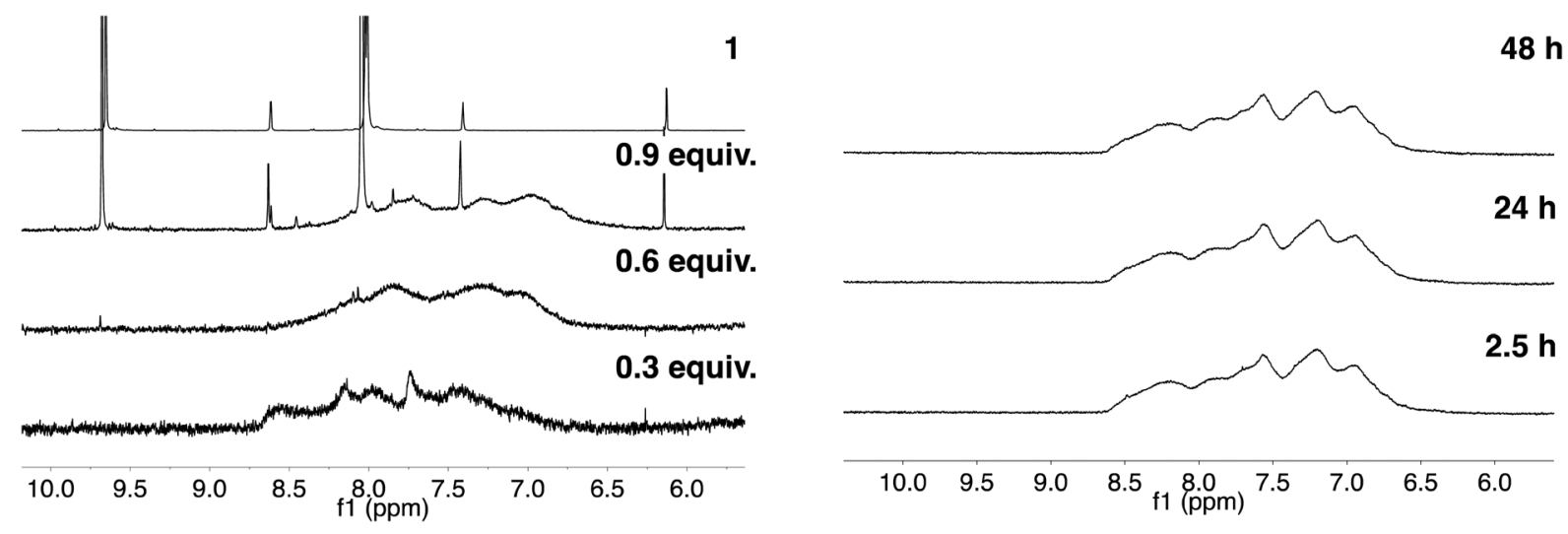

Fig. 3 Left: ${ }^{1} \mathrm{H}$ NMR spectra of 1 (Top) and of $\mathrm{P}_{40}$ treated with different amounts of 1 after $1 \mathrm{~h}$ of reaction. Adapted with permission from ref. 27. Right: ${ }^{1} \mathrm{H}$ NMR spectra of the reaction of $\mathrm{P}_{40}$ with 0.6 eq. 1 analysed at different intervals. 
under these conditions (i.e. $100 \mathrm{mM} \mathrm{AcOH}$ in $\mathrm{D}_{2} \mathrm{O}$ at $\mathrm{pH} 2.9$ and twofold dilution) (Fig. S11†).

We decided then to investigate the coupling of a series of hydrophilic aldehydes including anionic glyoxylic acid (2) neutral glyceraldehyde (3), or biologically similar betaine aldehyde chloride (4), pyridoxal-5'-phosphate (5) and 5-formyluracil (6) (Table 3). As expected, the coupling was highly dependent on the solubility of the aldehydes and/or the polymers obtained in the buffer used. When acidic conditions were employed (in this case 5\% AcOH, $24 \mathrm{~h}$ incubation. See discussion on organic solvent for details), only the neutral and cationic aldehydes 3 and $\mathbf{4}$ could give similar degrees of functionalisation to that reported for the imidazole derivative (1). Anionic aldehyde 5 and the uracil derivate $\mathbf{6}$ were insoluble in the acidic buffer employed while glyoxylic acid (2) resulted in insoluble polymers that compromised the characterisation of the degree of functionalisation. Switching to a basic buffer (100 mM Na $\mathrm{mPO}_{4}$ in $\mathrm{D}_{2} \mathrm{O}$ pH 9.1) compromised the overall coupling, and in this case, only anionic derivatives gave satisfactory degrees of functionalisation ranging from $63 \%$ for 2 to a very good $86 \%$ in the case of the phosphate derivative 5 . Interestingly, uracil derivative 6 remained insoluble in any of the conditions tested and we decided to explore the use of a polar organic solvent like DMSO to carry out the reactions. However, the prepared poly(acryloyl hydrazide)s $\mathbf{P}_{\boldsymbol{x}}$ showed very low solubility in this solvent and it had to be dissolved in aqueous conditions before any further dissolution with DMSO. Yet this way we could prepare solutions of $\mathbf{P}_{40}$ with up to $95 \%$

Table 3 Percentage loading in coupling reactions of $P_{40}$ with 1 eq. of water soluble aldehydes under different aqueous conditions

\begin{tabular}{|c|c|c|c|c|}
\hline Entry & Aldehyde & $\begin{array}{l}5 \% \mathrm{AcOH} \\
\text { in } \mathrm{D}_{2} \mathrm{O} \mathrm{pH} \\
2.9\end{array}$ & $\begin{array}{l}100 \mathrm{mM} \\
\mathrm{Na}_{2} \mathrm{HPO}_{4} \text { in } \\
\mathrm{D}_{2} \mathrm{O} \text { pH } 9.1\end{array}$ & $\begin{array}{l}95 \% \text { DMSO- } \\
d_{6} 5 \% \text { AcOH } \\
\text { in } \mathrm{D}_{2} \mathrm{O}\end{array}$ \\
\hline $\mathbf{P}_{40} \mathbf{1}$ & & $66 \%$ & - & $74 \%$ \\
\hline $\mathbf{P}_{40} 2$ & & $3 \%$ & $63 \%$ & $68 \%$ \\
\hline $\mathbf{P}_{40} 3$ & & $65 \%$ & $13 \%$ & $20 \%$ \\
\hline $\mathbf{P}_{40} 4$ & & $80 \%$ & - & $30 \%$ \\
\hline$P_{40} 5$ & & $-^{a}$ & $86 \%$ & $-^{a}$ \\
\hline $\mathbf{P}_{40} 6$ & HN & $-^{a}$ & $-^{a}$ & $65 \%$ \\
\hline
\end{tabular}

All experiments characterized after $24 \mathrm{~h}$ incubation at $60{ }^{\circ} \mathrm{C}$. Percentage functionalisation calculated by ${ }^{1} \mathrm{H}$ NMR peak integration. ${ }^{a}$ Insoluble aldehyde and/or insoluble products. of DMSO, without any obvious formation of precipitates by visual inspection.

The use of an organic co-solvent like DMSO opened new possibilities but required exploring the effect that this solvent had in the coupling conditions. Investigation of the kinetics of the reaction suggested that now the coupling of the hydrazides and the aldehydes was much slower and often long incubation at $60{ }^{\circ} \mathrm{C}$ was required to achieve similar degrees of functionalisation than those observed under aqueous conditions. For instance, when $\mathbf{P}_{\mathbf{4 0}}$ and 1 eq. of our model aldehyde 1 were dissolved in a $1: 1$ mixture of aqueous buffer $\left(5 \% \mathrm{AcOH}\right.$ in $\left.\mathrm{D}_{2} \mathrm{O}\right)$ and DMSO- $d_{6}$, less than half of the aldehyde had coupled after incubation for $24 \mathrm{~h}$ at $60{ }^{\circ} \mathrm{C}$ (Fig. S12, ESI $\dagger$ ). This could be improved by increasing the amount of DMSO- $d_{6}$ to $95 \%$, with approximately $76 \%$ of the aldehyde reacting in this case (Fig. S13, ESI $\dagger$ ). In view of this effect of the organic solvent in the rate of functionalisation, all the couplings reported in Table 3 were performed following $24 \mathrm{~h}$ incubation at $60{ }^{\circ} \mathrm{C}$.

Using these conditions ( $95 \%$ DMSO- $d_{6} / 5 \% \mathrm{AcOH}$ in $\mathrm{D}_{2} \mathrm{O}$ ) we could functionalise $\mathbf{P}_{\mathbf{4 0}}$ with the uracil derivative $\mathbf{6}$, reaching similar levels of functionalisation $(65 \%)$ to the previous cases (Table 3). These conditions proved to be quite versatile and all aldehydes except for the phosphate derivative 5 could be dissolved in this solvent. Yields varied again, with glyceraldehyde 3 giving a surprising low degree of functionalisation (20\%). We believe that in this case functionalisation of the polymer is outcompeted by the self-polymerisation of 3 via cyclic ketal formation, in agreement with the disappearance of the aldehyde signals and the appearance of a new signal at $3.53 \mathrm{ppm}$ (Fig. S14, ESI $\dagger$ ).

The use of an organic solvent opened also the possibility of evaluating the coupling conditions for hydrophobic aldehydes, often present in biologically relevant polymers such as gene vectors or antimicrobial polymers. A series of commercially available aldehydes ranging from aliphatic to aromatic aldehydes (Table 4) were evaluated for coupling to poly(acryloyl hydrazide) $\mathbf{P}_{40}$ using $95 \%$ DMSO- $d_{6} / 5 \% \mathrm{AcOH}$ in $\mathrm{D}_{2} \mathrm{O}$ as the reacting buffer. Overall, coupling efficiency for the aromatic aldehydes was around $70 \%$ regardless of the size of the aromatic aldehyde used (e.g. $\mathbf{P}_{40} 7$ vs. $\mathbf{P}_{40} 8$ ). We could efficiently incorporate substituted aromatics, including hydroxylated ( $\left.\mathbf{P}_{40} \mathbf{9}-\mathbf{P}_{40} 11\right)$, carboxylated $\left(\mathbf{P}_{40} \mathbf{1 2}\right)$ and fluorinated aldehydes $\left(\mathbf{P}_{\mathbf{4 0}} \mathbf{1 4}\right.$ and $\left.\mathbf{P}_{\mathbf{4 0}} \mathbf{1 5}\right)$. The degree of substitution seemed to have an effect in the coupling of the hydroxylated aromatics, with only 50\% loading observed for 2,4,5-trihydroxybenzaldehyde (11). A similar effect was observed for the fluorinated derivatives, suggesting both electronic and steric effects should be contributing to the efficiency of the functionalisation. Steric effects were more evident for the aliphatic aldehydes, with acetaldehyde (16) reaching almost a $90 \%$ of loading. Isovaleraldehyde (17) gave a smaller degree of functionalisation $(82 \%)$ with all of the other aliphatic aldehydes showing significantly less loading. However, solubility of the formed polymers with these long aliphatic aldehydes (18-20) was low, compromising the characterisation by NMR to determine the percentage of loading for these aldehydes. Nevertheless, broad- 
Table 4 Percentage loading in coupling reactions of $P_{40}$ with 1 eq. of different hydrophobic aldehydes

Entry

All experiments characterized after $24 \mathrm{~h}$ incubation at $60{ }^{\circ} \mathrm{C}$. Percentage functionalisation calculated by ${ }^{1} \mathrm{H}$ NMR peak integration. ${ }^{a}$ Insoluble products.

ening of ${ }^{1} \mathrm{H}-\mathrm{NMR}$ peaks belonging to the aliphatic chains supported evidence for hydrazone formation (Fig. S15, ESI $\dagger$ ). Some of these experiments were then repeated under the same conditions but using twice the amount of aldehyde (i.e. 2 eq.). Overall, increasing the amount of aldehyde had a beneficial effect over the coupling efficiency, which in some cases reached almost full conversion (Table S2, ESI $\dagger$ ).

\section{Impurities formed after coupling}

During the coupling reaction with aromatic aldehydes a new sharp signal was identified in the NMR spectra (Fig. S15, ESI $\dagger$ ). These sharp singlets between 9.0-8.5 ppm are consistent with $H-\mathrm{C}(\mathrm{R})=\mathrm{X}$ environments, and would suggest the formation of imines or hydrazones, through cleavage of the $\mathrm{NH}-\mathrm{NH}$ bond or the $\mathrm{CO}-\mathrm{NH}$ bond respectively (Scheme $\mathrm{S} 1 \dagger$ ). We therefore carried out coupling reactions with representative aldehydes and hydrazine monohydrate or ammonia respectively, using $95 \%$ DMSO- $d_{6} / 5 \% \mathrm{AcOH}$ in $\mathrm{D}_{2} \mathrm{O}$ as the reacting buffer. Coupling between hydrazine and benzaldehyde, and between hydrazine and 4-hydroxybenzaldehyde, resulted in the formation of hydrazones with NMR spectra that matched those of the impurities observed (Fig. S16, ESI $\dagger$ ). These two impurities could be identified in all the couplings with aromatic aldehydes, although in most cases the impurity's content was generally around $1-3 \%$ of total amount of aldehyde used (Table S3, ESI $\uparrow$ ). When coupling experiments with sub-stoichiometric (0.25 eq.) amounts of benzaldehyde were performed, both mono- and di-hydrazone were observed by NMR, even before all the aldehyde had coupled $(\sim 4 \mathrm{~h})$ (Fig. S17, ESI $\dagger$ ). The initial amount of impurity was very small $(<2 \%$ of the initial aldehyde). Once all the aldehyde had been consumed we observed a steady increase in the concentration of mono-hydrazone (e.g. benzylidenehydrazine), and up to $13 \%$ of the initial aldehyde had converted into this compound after 12 days. No significant increase in the intensity of the dihydrazone (e.g. 1,2-dibenzylidenehydrazine) was observed and remained around $3 \%$ even after 12 days.

At this stage, the mechanism of this side-reaction is unclear, but we believe that the mono-hydrazone is formed through cleavage of the $\mathrm{C}-\mathrm{N}$ bond in the polymer's hydrazone side-chains (Scheme S1†). The di-hydrazone will be then formed by subsequent reaction between any free aldehyde and the mono-hydrazone until no free aldehyde is present. We anticipate that cleavage will be probably facilitated by the presence of nucleophilic hydrazides in the vicinity of the hydrazone, and thus the amount of impurity is only significant when sub-stoichiometric amounts of aldehydes are employed.

\section{Effect of $M_{w}$ on coupling}

Finally, to explore the effect of polymer size on this post-polymerisation strategy, functionalisation of $\mathbf{P}_{\mathbf{8 0}}$ using $95 \%$ DMSO$d_{6} / 5 \% \mathrm{AcOH}$ in $\mathrm{D}_{2} \mathrm{O}$ as the reacting buffer was performed (Table S4, ESI $\dagger$ ). Overall coupling efficiencies were very similar to those reported for $\mathbf{P}_{\mathbf{4 0}}$, although bulky and aliphatic aldehydes yielded lower degrees of functionalization. This was particularly the case for 2-naphthaldehyde (8) and acetaldehyde (16) with over $20 \%$ lower coupling efficiencies than that observed for $\mathbf{P}_{\mathbf{4 0}}$ (Table 4). Similarly to $\mathbf{P}_{\mathbf{4 0}}$, coupling efficiency with $\mathbf{P}_{\mathbf{8 0}}$ could be improved by reacting with 2 eq. of aldehyde with, on average, an additional $10 \%$ of the side-chains functionalized this way. Kinetic studies were carried with several aldehydes and $\mathbf{P}_{\mathbf{8 0}}$ to investigate the time required to reach 
maximum possible conversion for each substrate. Most of the aldehydes reacted within $6 \mathrm{~h}$, with acidic 5-formylsalicylic (12) and aliphatic isovaleraldehyde (17) reaching their highest loading efficiency in less than $2 \mathrm{~h}$. On the other hand, indole3 -carboxaldehyde (13) required at least $24 \mathrm{~h}$ reaction time to reach maximum conversion. The level of impurities formed in theses couplings to $\mathbf{P}_{\mathbf{8 0}}$ (Table S4, ESI $\dagger$ ) were overall similar to those reported for $\mathbf{P}_{\mathbf{4 0}}$, being around 1-3\% of the total amount of aldehyde used in most cases.

\section{Conclusions}

Here, we have presented the synthesis and post-polymerisation functionalisation of poly(acryloyl hydrazide). RAFT polymerisation was employed to prepare a small library of Boc-protected poly(acryloyl hydrazide)s. Following deprotection under acidic conditions, we demonstrated that poly(acryloyl hydrazide) is a versatile reactive scaffold that can mediate the synthesis of polymers carrying a wide range of functionalities, including non-water soluble and biologically similar aldehydes. The efficiency of the hydrazide-aldehyde coupling was modulated by tuning the reaction conditions, including the use of both aqueous and organic conditions, to yield polymers with a consistent degree of functionalisation. We believe that our results will be of relevance to those screening for activity in polymers with high and/or complex patterns of functionalisation, such as those working in the discovery of polymeric materials for biomedical applications. Our efforts to elucidate the nature and mechanism of the side-reaction identified, the optimisation of the synthetic route, as well as further applications will be reported in due course.

\section{Contributions}

All authors contributed to the experimental set-up and discussed the results. DNC and FFT designed the polymer synthesis and characterisation. BM carried out GPC analysis of kinetic studies, and DNC and OC performed all other GPC analysis. DNC, JM and FFT designed the functionalisation experiments. DNC, OC, RB and JLB performed kinetic and stability experiments. DNC performed all of the other experiments. JM and FFT secured funding. DNC and FFT analysed the data and wrote the paper, with all other authors contributing to the final version of the manuscript.

\section{Conflict of interest}

There are no conflicts of interest to declare.

\section{Acknowledgements}

This work was supported by the Royal Society, U.K (IE130688) and the Wellcome Trust (177ISSFPP). F. F.-T. thanks the
Birmingham Science City and the European Regional Development Fund, the Royal Society (RG140273), and the University of Birmingham (John Evans Fellowship). J. M. thanks funding from MINECO (CTQ2014-59646-R, RYC-20131378) the Xunta de Galicia (ED431G/09 and 2016-AD031) and the ERC (Stg-DYNAP-677786). We thank Paul Wilson and David Haddleton (Warwick University) for the kind gift of 2,2'azobis(2,4-dimethylvaleronitrile) (V-65) and Cecile Le Duff (University of Birmingham) for her help with stability experiments. FFT and RB thank the India Travel Fund of the University of Birmingham. We also thank the following organisations for PhD scholarships: the University of Birmingham and John Evans (DNC), BBSRC (BB/M01116X/1) and the Midlands Integrative Biosciences Training Partnership (MIBTP) (OC), the University of Birmingham (JLB) and EPSRC (EP/L505110/1, M11296H) (BM).

\section{Notes and references}

1 S. R. S. Ting, G. Chen and M. H. Stenzel, Polym. Chem., 2010, 1, 1392-1412.

2 S. G. Spain and N. R. Cameron, Polym. Chem., 2011, 2, 6068.

3 L. L. Kiessling and J. C. Grim, Chem. Soc. Rev., 2013, 42, 4476-4491.

4 Q. Zhang and D. M. Haddleton, in Hierarchical Macromolecular Structures: 60 Years after the Staudinger Nobel Prize II, Springer International Publishing, Cham, 2013, vol. 262, pp. 39-59.

5 K. Taira, K. Kataoka and T. Niidome, Non-viral gene therapy, Springer Verlag, 2005.

6 K. Miyata, N. Nishiyama and K. Kataoka, Chem. Soc. Rev., 2012, 41, 2562-2574.

7 T. Wang, J. R. Upponi and V. P. Torchilin, Int. J. Pharm., 2012, 427, 3-20.

8 C. Alexander and F. Fernandez-Trillo, in Smart Materials for Drug Delivery, ed. C. Alvarez-Lorenzo and A. Concheiro, Royal Society of Chemistry, 1st edn, 2013, vol. 1, pp. 256-282.

9 H. Yin, R. L. Kanasty, A. A. Eltoukhy, A. J. Vegas, J. R. Dorkin and D. G. Anderson, Nat. Rev. Genet., 2014, 15, 541-555.

10 R. W. Scott, W. F. Degrado and G. N. Tew, Curr. Opin. Biotechnol., 2008, 19, 620-627.

11 J. M. Lagaron, M. J. Ocio and A. Lopez-Rubio, Antimicrobial Polymers, John Wiley \& Sons, Inc., Hoboken, New Jersey, 1st edn, 2011.

12 K. Kuroda and G. A. Caputo, Wiley Interdiscip. Rev.: Nanomed. Nanobiotechnol., 2013, 5, 49-66.

13 J. Chen, F. Wang, Q. Liu and J. Du, Chem. Commun., 2014, 50, 14482-14493.

14 Controlled and Living Polymerizations, ed. A. H. E. Müller and K. K. Matyjaszewski, Wiley-VCH Verlag GmbH \& Co. KGaA, Weinheim, Germany, 2009. 
15 L. E. N. Allan, M. R. Perry and M. P. Shaver, Prog. Polym. Sci., 2012, 37, 127-156.

16 Fundamentals of Controlled/Living Radical Polymerization, ed. N. V. Tsarevsky and B. S. Sumerlin, Royal Society of Chemistry, Cambridge, 2013.

17 Controlled Radical Polymerization: Mechanisms, ed. K. K. Matyjaszewski, B. S. Sumerlin, N. V. Tsarevsky and J. Chiefari, American Chemical Society, Washington, DC, 2015, vol. 1187.

18 M. A. Gauthier, M. I. Gibson and H.-A. Klok, Angew. Chem., Int. Ed., 2009, 48, 48-58.

19 P. Theato and H.-A. Klok, Functional Polymers by PostPolymerization Modification: Concepts, Guidelines, and Applications, Wiley-VCH Verlag GmbH \& Co. KGaA, Weinheim, Germany, 2013.

20 J. Romulus, J. T. Henssler and M. Weck, Macromolecules, 2014, 47, 5437-5449.

21 H. C. Kolb, M. G. Finn and K. B. Sharpless, Angew. Chem., Int. Ed., 2001, 40, 2004-2021.

22 R. K. Iha, K. L. Wooley, A. M. Nyström, D. J. Burke, M. J. Kade and C. J. Hawker, Chem. Rev., 2009, 109, 5620-5686.

23 E. M. Sletten and C. R. Bertozzi, Angew. Chem., Int. Ed., 2009, 6974-6998.

24 K. Kempe, A. Krieg, C. R. Becer and U. S. Schubert, Chem. Soc. Rev., 2012, 41, 176-191.

25 D. M. Patterson, L. A. Nazarova and J. A. Prescher, ACS Chem. Biol., 2014, 9, 592-605.

26 P. Espeel and F. E. du Prez, Macromolecules, 2015, 48, 2-14.

27 J. M. Priegue, D. N. Crisan, J. Martinez-Costas, J. R. Granja, F. Fernandez-Trillo and J. Montenegro, Angew. Chem., Int. Ed., 2016, 55, 7492-7495.

28 J. P. Adams, J. Chem. Soc., Perkin Trans. 1, 1999, 125-139.

29 K. Godula and C. R. Bertozzi, J. Am. Chem. Soc., 2010, 132, 9963-9965.

30 J. Shao and J. P. Tam, J. Am. Chem. Soc., 1995, 117, 38933899.

31 X. Liu, J. Liu and Y. Luo, Polym. Chem., 2012, 3, 310-313.

32 A. Kumar, R. R. Ujjwal, A. Mittal, A. Bansal and U. Ojha, ACS Appl. Mater. Interfaces, 2014, 6, 1855-1865.
33 X. Jia, X. Zhao, K. Tian, T. Zhou, J. Li, R. Zhang and P. Liu, Biomacromolecules, 2015, 16, 3624-3631.

34 R. R. Ujjwal, M. P. Purohit, S. Patnaik and U. Ojha, ACS Appl. Mater. Interfaces, 2015, 7, 11497-11507.

35 C. Gehin, J. Montenegro, E.-K. Bang, A. Cajaraville, S. Takayama, H. Hirose, S. Futaki, S. Matile and H. Riezman, J. Am. Chem. Soc., 2013, 135, 9295-9298.

36 I. Louzao, R. García-Fandiño and J. Montenegro, J. Mater. Chem. B, 2017, 5, 4426-4434.

37 M. R. Hill, S. Mukherjee, P. J. Costanzo and B. S. Sumerlin, Polym. Chem., 2012, 3, 1758-1762.

38 E. R. L. Brisson, Z. Xiao, G. V. Franks and L. A. Connal, Biomacromolecules, 2017, 18, 272-280.

39 D. A. Fulton, Org. Lett., 2008, 10, 3291-3294.

40 C. S. Mahon, A. W. Jackson, B. S. Murray and D. A. Fulton, Chem. Commun., 2011, 47, 7209-7211.

41 E. R. L. Brisson, Z. Xiao, L. Levin, G. V. Franks and L. A. Connal, Polym. Chem., 2016, 7, 1945-1952.

42 J. Skey and R. K. O'Reilly, Chem. Commun., 2008, 4183.

43 E. A. Hoff, B. A. Abel, C. A. Tretbar, C. L. McCormick and D. L. Patton, Polym. Chem., 2017, 128, DOI: 10.1039C6PY01563H.

44 A. Lowe and C. L. McCormick, Prog. Polym. Sci., 2007, 32, 283-351.

45 C. Barner-Kowollik, Handbook of RAFT polymerization, Wiley-VCH, Weinheim, 2008.

46 C. Boyer, V. Bulmus, T. P. Davis, V. Ladmiral, J. Liu and S. Perrier, Chem. Rev., 2009, 109, 5402-5436.

47 G. Yaşayan, M. Redhead, J. P. Magnusson, S. G. Spain, S. Allen, M. Davies, C. Alexander and F. Fernandez-Trillo, Polym. Chem., 2012, 3, 2596-2604.

48 D. J. Keddie, C. Guerrero-Sanchez, G. Moad, E. Rizzardo and S. H. Thang, Macromolecules, 2011, 44, 6738-6745.

49 B. A. Abel, M. B. Sims and C. L. McCormick, Macromolecules, 2015, 48, 5487-5495.

50 B. A. Abel and C. L. McCormick, Macromolecules, 2016, 49, 465-474.

51 P. W. Riddles, R. L. Blakeley and B. Zerner, Anal. Biochem., 1979, 94, 75-81. 